\title{
High apex predator biomass on remote Pacific islands
}

Charlotte Stevenson ${ }^{1}$, Laure S. Katz ${ }^{2}$, Fiorenza Micheli ${ }^{1,}{ }^{*}$, Barbara Block ${ }^{1}$, Kimberly W. Heiman ${ }^{1}$, Chris Perle ${ }^{1}$, Kevin Weng ${ }^{1}$, Robert Dunbar ${ }^{2}$, Jan Witting ${ }^{3}$

${ }^{1}$ Stanford University, Hopkins Marine Station, Pacific Grove, CA 93950, USA

${ }^{2}$ Stanford University, School of Earth Sciences, Stanford, CA 94301, USA

${ }^{3}$ Sea Education Association, Woods Hole, MA 0254, USA

*E-mail: micheli@stanford.edu

Abstract. On coral reefs in Palmyra — a central Pacific atoll with limited fishing pressure - total fish biomass is 428 and $299 \%$ greater than on reefs in nearby Christmas and Fanning Islands. Large apex predators -groupers, sharks, snappers, and jacks larger than $50 \mathrm{~cm}$ in length- account for $56 \%$ of total fish biomass in Palmyra on average, but only $7 \%$ and $3 \%$ on Christmas and Fanning. These biomass proportions are remarkably similar to those previously reported for the remote and uninhabited Northwest Hawaiian Islands (NWHI) and densely populated Main Hawaiian Islands (MHI), although Palmyra's reefs are dominated in biomass by sharks ( $44 \%$ of the total), whereas the NWHI by jacks (39\%). Herbivorous fish biomass was also greater on Palmyra than on Christmas and Fanning (343\% and 207\%, respectively). These results and previous findings indicate that remote, uninhabited islands support high levels of consumers, and highlight the importance of healthy coral reef ecosystems as reference points for assessment of human impacts and establishment of restoration goals.

Keywords. Coral reefs, food webs, fishing impacts, top predators, Palmyra, Line Islands. 


\section{Introduction}

Fisheries tend to deplete populations of large, long-lived species at the top of marine food webs (Pitcher 2001; Myers and Worm 2003). Depletion of apex predators can induce changes to the structure of marine communities as effects cascade through lower trophic levels (Stevens et al. 2000; Bascompte et al. 2005; Mumby et al. 2006). Historical analyses suggest that widespread depletion of apex predators through fishing often preceded the study and monitoring of coral reefs, making it difficult to establish a natural baseline for coral reef ecosystems (Pandolfi et al. 2003).

By comparing reefs along gradients of fishing intensity, Friedlander and DeMartini (2002) determined that the remote and lightly fished Northwest Hawaiian Islands (NWHI) support significantly more fish biomass than the heavily fished Main Hawaiian Islands (MHI), with apex predators comprising on average $54 \%$ of the total fish biomass in the NWHI, but only $3 \%$ in the MHI. Here, total biomass and trophic structure of reef fish assemblages were compared among three locations in the Line Islands - Christmas (Kiritimati) Island, Fanning (Tabuaeran) Island, which are part of the island nation of Kiribati, and Palmyra Atoll (Fig. 1). These islands experience different fishing pressures, yet similar oceanic conditions: all are located in the Intertropical Convergence Zone (ITCZ), influenced by the equatorial countercurrent. They represent ideal conditions in which to examine the effects of fishing on coral reef fish assemblages because they are similar biogeographically, but have recently diverged along a trajectory from heavily impacted (Christmas Island) to virtually unimpacted (Palmyra).

Christmas and Fanning Islands have been inhabited for as much as 2,000 years (Thomas 2003). Christmas Island has a current population of ca. 8,000, while Fanning Island's population recently escalated to ca. 3,000 due to a governmental citizen- 
relocation program (K. Anderson, personal communication; Chung 2000). At both islands, local fishermen use gill nets and hook-and-line to catch reef fishes, including sharks, and spear-fishing and long-lining occur throughout the surrounding waters (Thomas 2003). In 1995, shark-fin exports peaked with a total value exceeding US \$494,000 (Thomas 2003).

In contrast, Palmyra was privately owned for 100 years, subsequently purchased by The Nature Conservancy in 2000, and is now a National Wildlife Refuge managed by the US Fish and Wildlife Service (The Nature Conservancy 2006). Although the U.S. Navy significantly altered Palmyra's inner lagoon during World War II, the outer reefs where this study was conducted remained relatively undisturbed (Dawson 1959). With minimal historical and current population (two resident refuge managers and up to ten visiting scientists or volunteers), Palmyra has never had the extensive local fisheries of the more populated Line Islands.

In this study, the fish biomass of different trophic groups was estimated in each of the three atolls to examine the magnitude of food web alteration from fishing. Results were compared with those from other studies conducted in the Hawaiian and Fijian archipelagos to examine the generality of the effects within the Pacific basin.

\section{Materials and methods}

Quantification of fish biomass on shallow reefs

Visual surveys were conducted in shallow back reef sites in May 2003 and 2005. Three sites were surveyed at Christmas and Fanning Island in 2005, and four sites at Palmyra in 2003 and 2005 (Fig. 1). All sites were located outside the inner lagoons, on the leeward side of each island except the fourth Palmyra site, located in a 
windward location protected from a series of islets ("Coral Gardens"). Each site was surveyed with four to seven randomly placed $50 \times 4 \mathrm{~m}$ belt transects, all located between 2-8 m depth. Although alternative methods (e.g., timed searches) may estimate abundances of large, mobile fishes more accurately than belt transects, we used belt transects to ensure direct comparability with the surveys conducted by Friedlander and DeMartini (2002) in he Hawaiian Archipelago. A total of 15 transects at Christmas Island, 14 at Fanning Island, and 29 at Palmyra Atoll were surveyed. Two observers surveyed each transect by snorkeling along the transect line: one recorded the numbers and estimated sizes of fishes in the families Carangidae (jacks), Lutjanidae (snapper), Carcharhinidae (sharks), and Serranidae (grouper); the other recorded the numbers and sizes of other demersal fish larger than five $\mathrm{cm}$ in total length. To ensure independence of individual replicates surveyed, transects were never contiguous with each other.

Demersal fish were identified to the family level. Taxa were assigned to trophic groups based on diet and trophic level information reported in FishBase (Froese and Pauly 2003). Fish biomass was estimated using the length (L) - weight (M) equation: $\mathrm{M}=a \mathrm{~L}^{b}$. Constants $(a, b)$ for the species most commonly observed were obtained from FishBase (Froese and Pauly 2003) and averaged by family. Future studies should include identification of fish to the species level, as estimation of biomass at the family level disregards within-family variation in the $a$ and $b$ constants. However, in our analyses, averaging of $a$ and $b$ constants within families does not appear to influence results significantly. To examine the extent to which biomass estimates were affected by averaging constants, estimation of fish biomass was repeated using either the smallest or the largest $a$ and $b$ constants within in each family. Using different constants, for each family, yielded similar biomass estimates. In particular, 
the estimated percent biomass accounted for by apex predators (see Results and Discussion) varied between $55-67 \%$ of the total, in all cases greater than $50 \%$ of total fish biomass.

Biomass variation was compared among islands using Analysis of Variance (ANOVA), with island as the main factor (fixed, three levels: Christmas Island, Fanning Island, and Palmyra), and site nested within island (random, three levels: site 1, 2, and 3 within each island). This ANOVA model was used to examine variation in total biomass and in biomass of each trophic group. Due to the unbalanced design (4 sites were surveyed at Palmyra), analyses were repeated four times, each time eliminating one Palmyra site. Results were qualitatively similar and only the most conservative $P$-values are reported here. Also, because the number of transects surveyed at each site varied, four transects were randomly drawn at each site. Because preliminary studies to determine the level of replication needed for adequate power in the ANOVAs were not conducted, $\mathrm{N}=4$ was utilized following Friedlander and DeMartini (2002). Highly significant differences in fish biomass among islands (see Results and Discussion) indicate that the design had adequate power in this system as well. ANOVAs were conducted only on the 2005 data, for comparisons among and within the Line Islands, and only the 2005 data is reported in Figures 2 and 3. Data from surveys conducted at Palmyra in 2003 were included in the analyses of trophic composition and composition of the predatory guild at Palmyra.

Qualitative video surveys of deep reefs

To determine if predators simply move to deeper waters at fished locations, shallow transects were complemented with deeper transects conducted along the 
forereef of the leeward shores of Palmyra and Fanning island using a remotely operated vehicle (ROV) equipped with a digital video camera (VideoRay Pro, Phoenixville, PA, USA). In 2003, two transects were conducted at Palmyra from $20 \mathrm{~m}$ to $100 \mathrm{~m}$ depth $\left(5^{\circ} 52.720^{\prime} \mathrm{N}, 162^{\circ} 10.150^{\prime} \mathrm{W}\right)$. In 2005 , two transects were conducted between 10 and 50 meters at both Fanning $\left(3^{\circ} 50.518^{\prime} \mathrm{N}, 159^{\circ} 21.679^{\prime} \mathrm{W}\right)$ and Palmyra ( $\left.5^{\circ} 52.078^{\prime} \mathrm{N}, 162^{\circ} 07.030^{\prime} \mathrm{W}\right)$.

Comparison among Pacific regions

To examine the generality of these results, estimates of fish biomass were compared with published values from Hawaii (Friedlander and DeMartini 2002) and Fiji (Jennings and Polunin 1997). Both studies compared the fish biomass and trophic structure of coral reef-fish assemblages on ocean-facing reefs across fishing gradients. While the survey methods used in this study are directly comparable to those used in the Hawaii study, Jennings and Polunin (1997) used the point count method, used a smaller size threshold $(30 \mathrm{~cm})$ for categorizing piscivores, and limited herbivorous fish to parrotfish (Scaridae). In particular, the point count method likely underestimates the abundance of large, mobile predators. In both this study and the Hawaii study, herbivorous fish also included surgeonfish (Acanthuridae), damselfish (Pomacentridae), and chubs (Kyphosidae). Therefore, comparisons of the Fiji study with data from Hawaii and the Line Islands are made only regarding the general biomass trends among reefs and relative abundances of trophic groups, not the absolute magnitudes of biomass estimates.

\section{Results and Discussion}


In the Line Islands, total fish biomass decreases along a gradient of increasing fishing pressure (using population densities on the islands as proxies for local fishing intensity). The shallow reefs at Palmyra Atoll (2-10 people, no fishing allowed on reefs because of marine protected area status) sustain $428 \%$ and $299 \%$ more fish biomass per $200 \mathrm{~m}^{2}$ than Christmas ( 8,000 people) and Fanning ( 3,000 people) Islands, respectively (ANOVA $F_{2,6}=18.6, P=0.003$ ) (Fig. 2). Large apex predators, e.g., piscivorous fishes larger than $50 \mathrm{~cm}$ in length, account for most of the variation in fish biomass among the islands, contributing an average of $56 \%, 7 \%$, and $3 \%$ of the total biomass of Palmyra, Fanning, and Christmas Islands (ANOVA $\mathrm{F}_{2,6}=212.9, P$ $=0.0009)$ (Fig. 2). Large apex predators were encountered in all but three of the 29 transects surveyed at Palmyra, but in only two of the 29 transects at Christmas and Fanning Islands.

ROV transects revealed a high abundance of apex predators on Palmyra's deep reefs, and conversely, a scarcity at Fanning Island. At Palmyra, large groups of grey reef sharks (Carcharhinus amblyhynchos) were recorded between 13 and $30 \mathrm{~m}$ water depth. In one video-frame alone, at $15 \mathrm{~m}$ depth, 24 grey reef sharks were recorded. In contrast, no sharks were observed in Fanning Island's transects. Any possible attraction bias of large predators to the ROV or ship was likely equal between the two sites.

Despite high levels of predators, biomass of low trophic levels (i.e., herbivores) was also high in Palmyra, 343\% and 207\% greater, per $200 \mathrm{~m}^{2}$, than at Christmas and Fanning Islands, respectively $\left(F_{2,6}=24.4, P=0.001\right)$ (Fig. 2$)$. In contrast, the biomass of piscivorous fish smaller than $50 \mathrm{~cm}$ (primarily snappers and groupers) and 
of lower-level carnivores (benthic invertebrate feeders, planktivores, and corallivores) did not vary significantly among islands (Fig. 2).

Comparison of these results with those from studies in Hawaii (Friedlander and DeMartini 2002) and Fiji (Jennings and Polunin 1997) reveals similar patterns in the effects of fishing pressure on trophic structure of fish assemblages among the three archipelagos. In all three regions, total fish biomass and the proportion of biomass in top trophic levels decrease from the lightly to intensely fished reefs (Fig. 3). In the absence of intense fishing, Palmyra and some of the NWHI have the greatest apex predator biomass among the 28 Pacific reefs surveyed in these studies, $>50 \%$ of total fish biomass, whereas percent apex predator biomass was $26 \%$ in lightly-fished reefs of Fiji (Fig. 3). Although Palmyra and the NWHI support similar levels of apex predator biomass, the composition of this trophic group differs between these locations. Reef sharks (blacktip, Carcharhinus melanopterus; whitetip, Triaenodon obesus; and grey reef sharks, Carcharhinus amblyhynchos) dominate Palmyra's reefs, on average accounting for $82.5 \%$ of large apex predator biomass and $44 \%$ of total fish biomass. Snapper, primarily Lutjanus bohar, comprise 15\% of large apex predator biomass, with jacks and grouper accounting for only $2.5 \%$ of apex predator biomass. In contrast, the giant trevally (Caranx ignobilis) accounted for $71 \%$ of apex predator biomass and 39\% of the total fish biomass in the NWHI (Friedlander and DeMartini 2002).

Both Palmyra and the NWHI have high herbivore biomass (34\% of the total in Palmyra and 33\% in the NWHI, on average) (Fig. 3), supporting the finding that coral reef ecosystems with high top predator levels can also support high levels of herbivores (Mumby et al. 2006). Two possible mechanisms could account for the high herbivore biomass on apex predator-dominated reefs. Field and food-web modeling 
(ECOPATH) studies report that sharks and other large piscivores may have low predation rates on herbivorous fishes (Parrish et al. 1986; Opitz 1996), but may affect herbivores indirectly, by preying upon intermediate consumers and releasing herbivores from predatory control (e.g., Bascompte et al. 2005). However, this explanation seems unlikely for the Line Islands, where the biomass of intermediate consumers did not differ significantly among islands. Alternatively, high biomass of herbivores at Palmyra and the NWHI may be a direct result of reduced fishing at all trophic levels (Micheli et al. 2004; Mumby et al. 2006). Parrotfishes and other lowtrophic level species that are caught by residents of Fanning and Christmas Islands (personal observations) may benefit directly from protection at Palmyra.

These results confirm and expand on existing data, supporting the generality of the dramatic apex predator depletion first documented in the Hawaiian archipelago (Friedlander and DeMartini 2002). Despite large variation in the habitats surveyed, local species diversity and community composition, and intensity of fishing, trophic alteration associated with fishing was similar among different Pacific regions. The typical trophic pyramid appears to be inverted on unfished coral reefs, with most fish biomass at top levels. Rapid turnover of basal species, long life spans of apex predators and accumulation of biomass into multiple cohorts, and external subsidies - that is an ability of large, mobile predators to access production from sources other than the coral reef habitat - may contribute to this unique trophic structure. Coral reefs lacking a history of intense exploitation set new baselines for evaluating human impacts and provide insights into the ecological function of these ecosystems. Understanding the influence of apex predators on the structure and dynamics of healthy coral reefs and devising strategies for protecting and re-building 
depleted predator populations are critically important research and conservation priorities.

\section{Acknowledgements}

We thank the Sea Education Association and Stanford University for supporting the Stanford@SEA programs in May 2003 and 2005. We also thank those aboard the SSV Robert C. Seamans, The Nature Conservancy, P. Sacks, M. and E. Lange, K. Lavander, A. Friedlander, J. Maragos, E. Sala, and S. Sandin for advice and sharing information, and F. Boero, J. B.C. Jackson, P. Mumby, R.Myers, and B. Worm for improving earlier drafts. 


\section{References}

Bascompte J, Melian C, Sala E (2005) Interactions strength combinations and the overfishing of a marine food web. Proc Natl Acad Sci USA 102:5443-5447

Chung M (2000) Population and sustainable development: The critical role of good governance. Asia-Pacific Population Journal 15:21-34

Dawson EY (1959) Changes in Palmyra Atoll and its vegetation through the activities of man, 1913-1958. Pacific Naturalist 1:1-51

Friedlander AM, DeMartini EE (2002) Contrasts in density, size, and biomass of reef fishes between the northwestern and the main Hawaiian islands: the effects of fishing down apex predators. Mar Ecol Prog Ser 230:253-264

Froese R, Pauly D (eds) (2003) FishBase. World Wide Web electronic publication, www.fishbase.org

Jennings S, Polunin NVC (1997) Impacts of predator depletion by fishing on the biomass and diversity of non-target reef fish communities. Coral Reefs 16:71-82

Micheli F, Amarasekare A, Bascompte J, Gerber LR (2004) Including species interactions in the design and evaluation of marine reserves: some insights from a predator-prey model. Bull Mar Sci 74:653-669

Mumby PJ, Dahlgren CP, Harborne AR, Kappel CV, Micheli F, Brumbaugh DR, Holmes KE, Mendes JM, Broad K, Sanchirico JN, Buch K, Box S, Stoffle RW, Gill AB (2006) Fishing, trophic cascades, and the process of grazing on coral reefs. Science 311:98-101

Myers RA, Worm B (2003) Rapid worldwide depletion of predatory fish communities. Nature 423:280-283

Opitz S (1996) Trophic interactions in Caribbean coral reefs. ICLARM Tech Rep 43

Pandolfi JM, Bradbury RH, Sala E, Hughes TP, Bjorndal KA, Cooke RG, McArdle D, McClenachan L, Newman MJH, Paredes G, Warner RR, Jackson JBC (2003) Global trajectories of the long-term decline of coral reef ecosystems. Science 301:955-959

Parrish JD, Norris JE, Callaham MW, Callaham JK, Magarifuji EJ, Schroeder RE (1986) Piscivory in a coral reef fish community. In: Simenstad CA, Caillet GM (eds) Contemporary Studies on Fish Feeding. Dr W Junk Publishers, The Netherlands, pp285-297

Pitcher TJ (2001) Fisheries managed to rebuild ecosystems? Reconstructing the past to salvage the future. Ecol Appl 11:601-617

Stevens JD, Bonfil R, Dulvy NK, Walker PA (2000) The effects of fishing on sharks, rays, and chimaeras (chondrichthyans), and the implications for marine ecosystems. ICES J Mar Sci 57:476-494

The Nature Conservancy (2006) The Nature Conservancy in Palmyra Atoll. World Wide Web electronic publication, http://nature.org/wherewework/asiapacific/palmyra/

Thomas FR (2003) Kiribati: Some aspects of human ecology, forty years later. Atoll Res Bull 501:D1-D40 


\section{Figure Legends}

Fig. 1. Location of study sites in the Line Islands.

Fig. 2. Biomass and trophic structure of fish assemblages at Christmas Island, Fanning Island, and Palmyra Atoll. Average ( $\pm 1 \mathrm{SE})$ biomass (in $\left.\mathrm{g}\left(200 \mathrm{~m}^{2}\right)^{-1}\right)$ of piscivorous fish $>50 \mathrm{~cm}$ in total length (large apex predators), piscivorous fish $<50$ $\mathrm{cm}$, lower-level carnivores (benthic invertebrate feeders, corallivores, and planktivores combined), and herbivores is reported.

Fig. 3. Regional comparison of average biomass of large piscivores, herbivores, and all other consumers combined across heavily and lightly-fished (marked with asterisks) reefs in Fiji (striped; Jennings and Polunin 1997), Hawaii (checkered; FFS $=$ French Frigate Shoals, $\mathrm{P} \& \mathrm{H}=$ Paerl and Hermes Island; Friedlander and DeMartini 2002), and the Line Islands (solid). 